SHORT COMMUNICATION

\title{
The role of Colletotrichum species on the Colletotrichum leaf disease of Hevea brasiliensis - a preliminary study
}

\author{
T.A.D.P. Thambugala and N. Deshappriya* \\ Department of Botany, Faculty of Science, University of Kelaniya, Kelaniya.
}

Revised: 07 August 2008 ; Accepted: 19 January 2008

\begin{abstract}
Colletotrichum Leaf Disease (CLD) is considered as one of the major causes for the decline in yields of rubber in the Asian continent. Since early 1900's the pathogen Colletotrichum gloeosporioides has been considered as the causative agent of this disease in all rubber-growing countries in the world. However, observations of a recent survey in Sri Lanka revealed that the fungus Colletotrichum acutatum also plays a significant role in the development of CLD in rubber plantations. Therefore, a complete understanding of the involvement of the two Colletotrichum species in causing CLD is necessary. In order to assess the effect of the two species separately and in combination, an in-vitro investigation was carried out using young rubber leaves. The results suggest that $C$. acutatum is the major pathogen causing larger lesions. The results also showed that the two fungi can be synergistic in causing CLD if C. acutatum is introduced before C. gloeosporioides.
\end{abstract}

Keywords: Colletotrichum acutatum, Colletotrichum gloeosporioides, pathogenesis

\section{INTRODUCTION}

Hevea brasiliensis (Willd. ex Juss.) Muell. Arg. (the rubber tree) is the major source of natural rubber (NR) in the world. The rubber tree, is subject to a wide range of foliar diseases, which cause yield losses of rubber latex. Among the foliar diseases, Colletotrichum Leaf Disease (CLD) is considered as one of the major causes of declining yields of rubber in Asia ${ }^{1}$. The fungus $C$. gloeosporioides (Penzing and Sacc.) was identified as the causative agent of CLD after studying diseased rubber leaves from Sri Lanka². Thereafter, C. gloeosporioides has been proved to be the causative agent of CLD in many other parts of the world. However, a more recent survey in Sri Lanka revealed that the fungus C. acutatum
(Simmonds ex Simmonds) also plays a significant role in the development of CLD in rubber plantations ${ }^{3}$.

It is therefore essential to develop a quick, easy and accurate screening method for the pathogens to study and evaluate their effects. In this investigation a laboratory based in-vitro bioassay was developed and the effect of the two Colletotrichum species in causing CLD of rubber was assessed.

\section{METHODS AND MATERIALS}

Isolation of causative organisms of CLD: Diseased leaf pieces were surface sterilized by immersing in $20 \mathrm{ml}$ of $0.1 \% \mathrm{HgCl}_{2}$ solution in a petridish for about $30 \mathrm{sec}$. The leaf pieces were thereafter washed with 3 serial washings in sterilized distilled water and dried on a sterilized filter paper. The sterilized leaf pieces were cut into small portions so as to include the margins of diseased area using a sterilized blade. These pieces were cultured on plates of Potato Dextrose Agar (PDA) supplemented with Streptomycin at a concentration of $0.12 \mathrm{~g} / \mathrm{L}$. The inoculated plates were incubated at room temperature. Two to three days later the fungal colonies that grew from the cultured leaf pieces were transferred to fresh PDA plates and pure cultures were obtained by using the hyphal tip method.

Identification of isolated fungi: Sticky tape $\operatorname{method}^{4}$ was used to identify the isolated fungi. The morphological characteristics and identification keys ${ }^{5}$ were used. The identifications were confirmed by using reference cultures at the Rubber Research Institute of Sri Lanka (RRISL), Agalawatta. 
Determination of pathogenicity of the Colletotrichum species: Conidial suspensions of test fungi were prepared by flooding $7 \mathrm{~d}$ old cultures with sterile distilled water. The concentration of conidia in the suspension was adjusted using sterilized distilled water to $10 \times 10^{4}$ conidia $/ \mathrm{mL}$ and $0.02 \mathrm{~mL}$ of each suspension was placed on the abaxial surface of copper brown leaves (obtained $14 \mathrm{~d}$ after bud break) of $H$. brasiliensis in the following manner:

Treatment 1- Spore suspension of C. acutatum Treatment 2- Spore suspension of C. gloeosporioides Treatment 3-Mixed spore suspension of $C$. gloeosporioides and $C$. acutatum $(1: 1)$

Treatment 4- Control (Sterile distilled water)

For each treatment, 4 leaves were used and 4 drops of the relevant conidial suspension were placed on both sides of axis of each leaf. The inoculated leaves were incubated at room temperature in moist chambers for $4 \mathrm{~d}$. Depending on the sizes of the lesions produced they were grouped into 4 categories as follows:
(a) - No lesions
(b) - Lesion diameter between $5 \mathrm{~mm}-10 \mathrm{~mm}$
(c) - Lesion diameter between $10 \mathrm{~mm}-15 \mathrm{~mm}$
(d) - Lesion diameter $>15 \mathrm{~mm}$

Mean sizes of lesions were also determined for different spore concentrations $\left(1 \times 10^{4}, 2.5 \times 10^{4}, 5.0 \times 10^{4}, 1 \times 10^{5}\right.$, $2.5 \times 10^{5}, 5.0 \times 10^{5}$ and $1 \times 10^{6}$ conidia $/ \mathrm{mL}$ ) of the two Colletotrichum spp. on detached young leaves of H. brasiliensis.

The combined effect of the two Colletotrichum species was also investigated following the same procedure as described previously. The treatments were as follows:
Treatment 1 - C. acutatum (Initial inoculation) + C. gloeosporioides (after 3 days)

Treatment 2 - C. gloeosporioides (Initial inoculation) + C. acutatum (after 3 days)

Treatment 3 - C. gloeosporioides + C. acutatum (Added simultaneously)

Treatment 4 - Control (Sterile distilled water)

The lesions were also categorized as described earlier.

\section{RESULTS}

\section{Isolation of causative organisms of CLD}

Cultures of $C$. acutatum and C. gloeosporioides were isolated from infected Hevea leaves. Majority of the isolates were $C$. acutatum.

\section{Pathogenicity of the two Collectotrichum species}

C. acutatum produced significantly larger lesions than those produced by $C$. gloeosporioides. The lesions produced by $C$. acutatum were dark and moist while C. gloeosporioides produced colorless moist lesions. Lesions were not produced when mixed inocula were used (Table 1).

\section{Effect of inoculum concentration on pathogenicity of the two Colletotrichum species}

The ability to produce lesions by the 2 species varied with the spore concentrations. The ability to produce a lesion decreased significantly as the inoculum concentration increased beyond $10 \times 10^{4}$ conidia $/ \mathrm{mL}$. The maximum size of lesions was produced at $10 \times 10^{4}$ conidia $/ \mathrm{mL}$. Both

Table 1: Comparison of size of lesions produced by C. acutatum and C. gloeosporioides separately and in combination on young leaves of $H$. brasiliensis

\begin{tabular}{ccccc}
\hline \multirow{2}{*}{ No of replicate } & \multicolumn{4}{c}{ Category based on the size of lesions ${ }^{\mathrm{x}}$ produced } \\
\cline { 2 - 5 } & C. acutatum & C. gloeosporioides & $\begin{array}{l}\text { C. gloeosporioides } \\
\text { and C. acutatum }\end{array}$ & Control \\
\cline { 2 - 5 } 1 & $\mathrm{~d}$ & $\mathrm{c}$ & $\mathrm{a}$ & $\mathrm{a}$ \\
2 & $\mathrm{~d}$ & $\mathrm{~d}$ & $\mathrm{a}$ & $\mathrm{a}$ \\
3 & $\mathrm{c}$ & $\mathrm{c}$ & $\mathrm{a}$ & $\mathrm{a}$ \\
4 & $\mathrm{~d}$ & $\mathrm{c}$ & $\mathrm{a}$ & $\mathrm{a}$ \\
\hline
\end{tabular}

${ }^{x}$ The responses produced by each fungus separately and in combination on young leaves of Hevea after inoculation of leaves with $10 \times 10^{4}$ conidia/mL inoculum drop and incubation for 4 days at room temperature $\left(28 \pm 2^{\circ} \mathrm{C}\right)$ are:
(a) - No lesion production
(b) - Lesion diameter between $5 \mathrm{~mm}-10 \mathrm{~mm}$
(c) - Lesion diameter between $10 \mathrm{~mm}-15 \mathrm{~mm}$
(d) - Lesion diameter $>15 \mathrm{~mm}$ 
Table 2: Comparison of size of lesions produced by C. acutatum and C. gloeosporioides on young leaves of Hevea at different inoculum concentrations

\begin{tabular}{lcccc}
\hline Concentration & \multicolumn{4}{c}{ Category based on the size of lesions ${ }^{\mathrm{y}}$ produced. } \\
\cline { 2 - 5 }$\left(\right.$ Conidia/mL $\left.\mathrm{mL}^{-1}\right)$ & C. acutatum & C. gloeosporioides & $\begin{array}{l}\text { C. gloeosporioides } \\
\text { and C. acutatum }\end{array}$ & Control \\
\hline $1 \times 10^{4}$ & $\mathrm{~b}$ & $\mathrm{a}$ & $\mathrm{a}$ & $\mathrm{a}$ \\
$2.5 \times 10^{4}$ & $\mathrm{~b}$ & $\mathrm{~b}$ & $\mathrm{a}$ & $\mathrm{a}$ \\
$5.0 \times 10^{4}$ & $\mathrm{c}$ & $\mathrm{b}$ & $\mathrm{a}$ & $\mathrm{a}$ \\
$1 \times 10^{5}$ & $\mathrm{~d}$ & $\mathrm{c}$ & $\mathrm{a}$ & $\mathrm{a}$ \\
$2.5 \times 10^{5}$ & $\mathrm{~b}$ & $\mathrm{a}$ & $\mathrm{a}$ & $\mathrm{a}$ \\
$5.0 \times 10^{5}$ & $\mathrm{a}$ & $\mathrm{a}$ & $\mathrm{a}$ & $\mathrm{a}$ \\
$1 \times 10^{6}$ & $\mathrm{a}$ & $\mathrm{a}$ & $\mathrm{a}$ & $\mathrm{a}$ \\
\hline
\end{tabular}

${ }^{y}$ The responses produced by each fungus separately and in combination on young leaves of Hevea after inoculation of leaves with different inoculum concentrations $\left(1 \times 10^{4}\right.$ to $\left.1 \times 10^{6}\right)$ and incubation for 4 days at room temperature $\left(28 \pm 2^{\circ} \mathrm{C}\right)$ are:
(a) - No lesion production
(b) - Lesion diameter between $5 \mathrm{~mm}-10 \mathrm{~mm}$
(c) - Lesion diameter between $10 \mathrm{~mm}-15 \mathrm{~mm}$
(d) - Lesion diameter $>15 \mathrm{~mm}$

Table 3: Comparison of size of lesions produced by different treatments at two time intervals

\begin{tabular}{ccccc}
\hline Time intervals & \multicolumn{4}{c}{ Category based on the size of lesions ${ }^{2}$ produced } \\
\cline { 2 - 5 } (days) & Treatment 1 & Treatment 2 & Treatment 3 & Treatment 4 \\
\hline 3 d after $1^{\text {st }}$ inoculation & $\mathrm{c}$ & $\mathrm{b}$ & $\mathrm{a}$ & $\mathrm{a}$ \\
$3 \mathrm{~d}$ after $2^{\text {nd }}$ inoculation & $\mathrm{d}$ & $\mathrm{b}$ & $\mathrm{a}$ & $\mathrm{a}$ \\
\hline
\end{tabular}

${ }^{z}$ The responses produced by different treatments at two time intervals are:

(a)- No lesion production

(b)- Lesion diameter between $5 \mathrm{~mm}-10 \mathrm{~mm}$

(c)- Lesion diameter between $10 \mathrm{~mm}-15 \mathrm{~mm}$

(d)- Lesion diameter $>15 \mathrm{~mm}$

C. acutatum and C. gloeosporioides did not produce lesions at high spore concentrations (Table 2).

\section{Combined effect of the two Colletotrichum species}

The inoculation of $C$. acutatum initially, followed by C. gloeosporioides 3 days later increased the size of the lesions produced by $C$. acutatum. But the size of the lesions produced by $C$. gloeosporioides remained unchanged when $C$. acutatum was inoculated 3 days afterwards. Lesions were not produced when a mixed inoculum of the two fungi and sterile distilled water were applied (Table 3).

\section{DISCUSSION}

Rubber plants in all rubber growing countries are affected by the CLD, resulting in secondary leaf fall reducing yields significantly ${ }^{6}$. Considering the seriousness of this disease, it is essential to understand the effect of the two Colletotrichum species in causing CLD. However, pathogenesis by Colletotrichum has received very little attention except for few studies carried out on Hevea isolates and strawberry isolates ${ }^{7}$.

The results of this investigation show that the two species of Colletotrichum behave differently on Hevea leaves. C. acutatum produced darker moist lesions and C. gloeosporioides produced colourless moist lesions. This may be due to the variability in pathogenicity between $C$. acutatum and $C$. gloeosporioides. These results are similar to the observations made by Brown and Soepena ${ }^{8}$.

The conidia of both C. acutatum and C. gloeosporioides showed self-inhibition at high conidial concentrations leading to decreasing lesion development. This is a 
well-known phenomenon among fungal pathogens and is considered to be present in all fungi as an adaptation to increase pathogenicity by enabling the dispersal of ungerminated conidia, which are more resistant to fluctuations of environment than germinated ones ${ }^{9}$.

Lesions were not produced when a mixed inoculum was used. A likely reason for the inhibition of lesion production when a mixture of conidia was used for inoculation would be, the involvement of inhibitory substances present at the conidium surface as reported by Bailey et al ${ }^{7}$. Further, the inhibition of conidia germination, when a mixed inoculum is used would also be due to the competition between two Colletotrichum species for space and nutrients.

The inoculation of $C$. acutatum initially followed by $C$. gloeosporioides 3 days later resulted in enhanced lesion production. The reason for this could be that C. acutatum predisposes the leaves enabling easier infection by $C$. gloeosporioides. Therefore, C. acutatum can be considered as the main causative agent of CLD. The results of this study show that $C$. acutatum and C. gloeosporioides can act synergistically in causing CLD. However, this aspect has to be studied further to determine the mechanism of the synergistic effect.

\section{Acknowledgement}

The authors wish to acknowledge the assistance rendered by Dr C.K. Jayasinghe, Head of Plant Pathology and Microbiology Department, Rubber Research Institute of Sri Lanka, Dartonfield, Agalawatte.

\section{References}

1 Samaradeewa P.K., Liyanage A. de S. \& Wickremasinghe W.N. (1985). Relationships between the incidence and severity of Colletotrichum gloeosporioides leaf disease in Hevea brasiliensis. Journal of the Rubber Research Institute of Sri Lanka 63: 1-8.

2 Petch T. (1906). Description of new Ceylon fungi. Annual Report of Botanical Gardens Peradeniya 3: 1-10.

3 Jayasinghe C.K., Fernando T.H.P.S. \& Priyanka U.M.S. (1997). Colletotrichum acutatum is the main cause of Colletotrichum leaf disease of rubber in Sri Lanka. Mycopathologia 137(1): 53-56.

4 Flegel T.W. (1980). Semi permanent microscope slides of microfungi using sticky tape technique. Canadian Journal of Microbiology 26(4): 551-553.

5 Domsch K.H., Gams W. \& Anderson T.H. (1993). Compendium of Soil Fungi, Vol 1 \& 2. pp. 690 Academic Press, New York, USA.

6 Jayasinghe C.K. \& Fernando T.H.P.S. (1998). Growth at different temperatures and on fungicide amended media: two characteristics to distinguish rubber isolate of Colletotrichum acutatum and C. gloeosporioides. Mycopathologia 143(2): 93-95.

7 Bailey J.A., O' Connell R.J. \& Nash C. (1992). Colletotrichum: Biology, Pathology and Control (Eds. J.A. Bailey \& M.J. Jeger) pp. 289-357. Redwood Press, London. UK.

8 Brown A.E. \& Soepena H. (1994). Pathogenicity of Colletotrichum acutatum and C. gloeosporioides on leaves of Hevea spp. Mycological Research 98: 264-266.

9 Cochrane V.W. (1958). Physiology of Fungi. John Wiley and Sons, New York, USA. 